\title{
Why healthcare leadership should embrace quality improvement
}

\author{
Making quality improvement a core tenet of how healthcare organisations are run is essential to ensuring safe, high quality, and \\ responsive services for patients, write John $\mathbf{R}$ Drew and Meghana Pandit
}

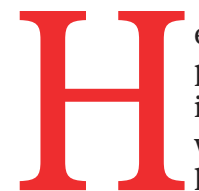

ealthcare staff often have a positive experience of quality improvement (QI) compared with the daily experience of how their organisations are led and managed. ${ }^{1}$ This indicates that some of the conditions and assumptions required for QI are at odds with prevailing management practices. For QI to become pervasive in healthcare, we need to change leadership and management.

At a QI event, we listened to an experienced nurse explaining a QI project to improve patient flow. The most striking thing was not her description of the project or what she had learnt or the benefits for patients, but instead how it had made her feel "valued and respected."

A manager's job is to achieve organisational goals. In the NHS, this includes meeting emergency and elective targets, such as the referral to treatment target, cancer and diagnostic standards, and the emergency department standard. Clinicians often perceive managerial interactions as authoritarian and lacking patient centredness and see QI as inclusive, bottom-up engagement. ${ }^{2}$ Staff appreciate non-hierarchical approaches.

QI can be defined as "a systematic approach that uses specific techniques to improve quality."2 It requires infrastructuresystematic and disciplined ways to eliminate waste from processes, improve outcomes and experiences for patients, and eradicate mistakes. It requires organisational patience and a culture that empowers staff to achieve positive change. Organisations that foster continuous improvement might say that all staff have two jobs: first, to do their job; second, to improve it.

The nurse we spoke to said that the main difference when working on the QI project was having the time and the "permission" to make improvements in her own work. Staff engagement scores indicate that many NHS clinicians increasingly feel trapped in a flawed system with little prospect of changing it. ${ }^{3}$

Understanding why there is a gap between the predominant management practices and culture of the NHS and the "microclimate" associated with local QI activities, and how to close that gap, is vital. Staff often report two contributors to this gap: a lack of "headspace" and feeling like a cog in a machine. ${ }^{4}$

Rising demand for healthcare and an estimated $8 \%$ vacancy rate ${ }^{5}$ in the clinical workforce make it difficult to find time for QI. Some leaders have committed to protecting time for QI because it generates a return in improved quality and productivity. ${ }^{6}$ But this is still rare. Without long term strategic commitment, expecting people to find time for their second job is unrealistic. There is growing recognition that this needs to change. ${ }^{78}$

Increased demand has been compounded by a rise in transparency and regulation, especially in publicly funded health systems, placing managers and leaders under greater pressure. Regulators often require improvement plans to be developed quickly, making meaningful staff engagement difficult. Recent changes in contracts, such as job planning, and pension tax rules in the UK have led many doctors to think that their employment has become more transactional. This, combined with top-down target setting and a narrative of "grip and control," might explain why staff increasingly feel insignificant.

\section{Ql as the basis of management}

QI depends on engaging and empowering the teams delivering care and equipping them with the tools and skills they need to improve care pathways. Ultimately, it means trusting professionals' knowledge and judgment of what patients need and allowing them to make decisions, including the allocation of resources, with appropriate accountability. This requires a shift in managerial and leadership thinking (box 1).

QI needs to become the basis of how organisations are led and managed, replacing traditional, hierarchical structures and incentives. Regulators already recognise this; the Care Quality Commission's report on quality improvement in hospital trusts, for example, says that when leaders and frontline staff work together it creates a powerful sense of shared purpose. ${ }^{6}$ This is often present in the NHS trusts that it rates "outstanding," it says. Dido Harding, chair of NHS Improvement, has said, "If all of the boards in the NHS chose to take culture and people management more seriously and put it on a level footing with financial and operational performance, we'd see a huge improvement in culture and outcomes for patients as well."9

The profound shifts in leadership and management needed for QI to thrive sometimes run contrary to traditional approaches for optimising short term performance. The recent average tenure of an NHS chief executive is 2-3 years, undermining the sustainable culture change needed for QI. ${ }^{10}$ Burgess and colleagues describe a different type of governance that fosters learning, citing the partnership of NHS Improvement and five trusts with the Virginia Mason Institute in the United States. ${ }^{11}$ Creating a compact with regulators enables a change in attitudes and allows organisations to grow and learn, they say. This promotes board longevity, which is a requirement for continuous improvement. ${ }^{6}$

\section{When do QI and good management coalesce?}

The most senior leaders might have the greatest challenge; their roles would shift from being responsible for all performance to a devolved model of collective, inclusive, and compassionate leadership. Embedding QI can challenge senior leaders' fundamental beliefs and management practices. Safe healthcare depends on defining and following standards, but an emphasis on engaging frontline staff to develop, apply, and improve those standards is often lacking. Instead, standards are implemented rapidly in a top-down, nonnegotiable fashion. ${ }^{12}$

The language of QI often reflects nature, describing organisations as ecosystems to cultivate or living systems to keep healthy rather than machines to optimise. Human factors (such as relationships, trust, and healthy multidisciplinary teams), talent management, succession planning, and assurance are central to this way of working.

Senior leaders must be role models. Their behaviour is amplified throughout the organisations they lead, whether they recognise it or not. Staff will judge what is important by where and how leaders spend their time rather than by what they say.

The Virginia Mason Institute partnership was enabled in 2015 by the secretary of state 
Box 1: Cycles of continuous improvement

All QI activities need to start small and then scale up. The transition to full implementation requires constant plan-do-study-act cycles with user involvement and feedback. One QI activity that changed organisational culture received the HSJ National Patient Safety Team Award in 2018.

The process began with the team members asking themselves, if they were a patient, what would they like to happen after a clinical harm incident in a hospital. The team then defined the current state and future vision. Eight frontline staff participated in a five day workshop to define the key steps that would help achieve the desired outputs. They tested the approach over the next few weeks and agreed metrics that were reported to executives at 30,60, and 90 days. The workshop included patient representatives. Several changes resulted in increased incident reporting and user feedback, introduction of safety huddles, and the creation of an innovative patient safety response team.

Making such changes stick requires constant and consistent messaging and leading by example. Appreciating the efforts of frontline workers, and saying "thank you," is vital.

for health and social care to adopt "lean thinking” (a method developed by Toyota to deliver more benefits to society while eliminating waste) in the NHS. The trusts' progress is being evaluated, but some trusts already report having developed a "golden thread" of QI that is visible to all, leading to improvements in CQC ratings and staff engagement.

Translating QI endeavours into operational and financial success takes time, and caregivers, providers, and regulators need to hold their nerve to see lasting performance improvement. Other healthcare providers have embraced QI methods without formal partnerships with international organisations and have delivered strong long term results. A key feature in most of these cases has been coaching for the most senior leaders and managers (for example, with a "lean" coach, usually people with experience from other industries who have moved into healthcare or consultants) so that they understand the changes they need to make in their own behaviours and practices. This has been described in the motor industry. ${ }^{13}$

\section{So is QI just good management?}

Management, leadership, and QI are distinct but overlapping. Some leaders are not managers, and vice versa. Some, but not all, leaders and managers will undertake QI, which can be performed in isolation from leadership and management. But integrating all three is likely to optimise outcomes. Broadly, management is controlling a group or team to accomplish a goal. Leadership is influencing others to contribute towards success. Management requires "grip" (staying on top of details, intervening quickly, and giving orders or instructions if performance is below expectations), and QI often requires a deliberate loosening of that grip. This could create conflict unless management has QI as a fundamental principle.
One could argue that QI requires more people to behave like leaders and fewer to behave like managers. In the most radical forms of QI (such as those described in Reinventing Organisations ${ }^{14}$ ), many of the roles and responsibilities of management become shared among well functioning, trusted frontline teams. The sense of "them and us" between frontline workforce and management vanishes.

The chairman of the Japanese electronics company Matsushita famously issued a challenge: "The essence of management is getting ideas out of the heads of the bosses and into the heads of labour ... Business, we know, is now so complex and difficult, the survival of firms so hazardous in an environment increasingly unpredictable, competitive, and fraught with danger, that their continued existence depends on the day-to-day mobilisation of every ounce of intelligence.”15

\section{How can we help leaders get on this path?}

Embedding QI in any organisation requires a new narrative from regulators and boards, strategic intent, investment in training leaders and staff, a more distributed leadership model that empowers frontline teams, and a meaningful role for patients so that improvement activity is aligned to what they most need and value. ${ }^{616}$

It also requires courage and patience from the most senior leaders as they commit to new management practices. Their incentives must depend not only on delivery of topdown targets but also on building a culture conducive to long term quality improvement, which could be personally uncomfortable for them. ${ }^{17}$

Quality management systems have an important role. ${ }^{18}$ Taichi Ohno, architect of the Toyota Production System (popularised as "lean"), would instruct managers to spend hours "watching" from within a chalk circle on the factory floor. He wanted managers to learn to see waste and opportunities to improve quality and flow.
Learning good management in healthcare includes not only learning to see opportunities to improve healthcare processes but also noticing the experience of frontline staff, and consequently leading in ways that engage and empower them to "mobilise every ounce of intelligence."

This article is one of a series commissioned by The BMJ based on ideas generated by a joint editorial group with members from the Health Foundation and The $B M J$, including a patient/carer. The BMJ retained full editorial control over external peer review, editing, and publication. Open access fees and The BMJ's quality improvement editor post are funded by the Health Foundation.

Competing interests: We have read and understood $\mathrm{BMJ}$ policy on declaration of interests and declare the following interests: none.

John R Drew, improvement and culture consultant Meghana Pandit, chief medical officer

Oxford University NHS Foundation Trust, John Radcliffe Hospital, Headley Way, Oxford OX3 9DU, UK

Correspondence to: JR Drew

john_drew@tiscali.co.uk

\section{(c) (1) (8)} This is an Open Access article distributed in accordance (CC BY-NC 4.0) license, which permits others to distribute, remix, adapt, build upon this work noncommercially, and license their derivative works on different terms, provided the original work is properly cited and the use is non-commercial. See: http:// creativecommons.org/licenses/by-nc/4.0/.

\section{Check for updates}

King's Fund. Making the case for quality improvement: lessons for NHS boards and leaders. 11 Oct 2017. https://www.kingsfund.org.uk/publications/makingcase-quality-improvement

2 The Health Foundation. Quality improvement made simple: what everyone should know about health care quality improvement. https://www.health.org.uk/sites/ default/files/QualitylmprovementMadeSimple.pdf

3 NHS Improvement. Developing people, improving care. https://improvement.nhs.uk/resources/developingpeople-improving-care/

4 Batalden PB, Davidoff F. What is "quality improvement" and how can it transform healthcare? Qual Saf Health Care 2007;16:2-3. doi:10.1136/ qshc. 2006.022046

5 Rolewicz L, Palmer B. The NHS workforce in numbers. Nuffield Trust. 8 May 2019. https://www.nuffieldtrust. org.uk/resource/the-nhs-workforce-in-numbers

6 Care Quality Commission. Quality improvement in hospital trusts: sharing learning from trusts on a journey of QI. Sep 2018. https://www.cqc.org.uk/ publications/evaluation/quality-improvement-hospital trusts-sharing-learning-trusts-journey-qi

7 NHS Improvement. NHS interim people plan. Jun 2019 https://www.longtermplan.nhs.uk/publication/interimnhs-people-plan/

8 West M. If it's about NHS culture, it's about leadership. King's Fund Blog. 20 Jan 2016. https://improvement. nhs.uk/resources/culture-leadership/

9 Lintern S. Boards should take culture as seriously as finance. Health Service Journal 3 Jun 2019. https://www.hsj.co.uk/workforce/exclusive-didoharding-boards-should-take-culture-as-seriously-asfinance/7025202.article

10 Timmins $N$. The chief executive's tale, views from the frontline of the NHS. King's Fund. May 2016. https:// 
www.kingsfund.org.uk/sites/default/files/field/ field_publication_file/The-chief-executive-tale-KingsFund-May-2016.pdf

11 Burgess N, Currie G, Crump B, Richmond J, Johnson M. Improving together: collaboration needs to start with regulators. BMJ 2019;367:16392. doi:10.1136/bmj. 16392

12 Anandaciva S, Ward D, Randhawa M, Edge R. Leadership in today's NHS: delivering the impossible. 18 Jul 2018. https://www.kingsfund.org.uk/ publications/leadership-todays-nhs
13 Spear S. Learning to lead at Toyota. Harvard Business Review. May 2004. https://hbr.org/2004/05/learningto-lead-at-toyota

14 Laloux F. Reinventing organisations. Nelson Parker, 2014

15 Pascale R. Managing on the edge: how successful companies use conflict for competitive advantage. Simon and Schuster, 1990.

16 Drew J, McCallum B, Roggenhofer S. Journey to lean. Palgrave Macmillan, 2004. doi:10.1057/9781403948410.
17 Lees P. The kicking has to stop. Faculty of Medical Leadership and Management. 25 Oct 2015. https:// www.fmlm.ac.uk/news-opinion/the-kicking-has-to-stop

18 Kaplan HC, Brady PW, Dritz MC, et al. The influence of context on quality improvement success in health care: a systematic review of the literature. Milbank Q 2010;88:500-59. doi:10.1111/j.1468$0009.2010 .00611 . x$

Cite this as: $B M / 2020 ; 368: m 872$

http://dx.doi.org/10.1136/bmj.m872 